\title{
Potentiality of Mindfulness Art Therapy Short Version on Mood of Healthy People
}

\author{
Michiyo Ando ${ }^{*}$, Sayoko Ito ${ }^{2}$ \\ ${ }^{1}$ St. Mary's College, Kurume City, Japan \\ ºkinawa Women's Junior College, Naha, Japan \\ Email: ${ }^{*}$ andou@st-mary.ac.jp
}

Received 3 April 2014; revised 5 May 2014; accepted 13 May 2014

Copyright (C) 2014 by authors and Scientific Research Publishing Inc.

This work is licensed under the Creative Commons Attribution International License (CC BY).

http://creativecommons.org/licenses/by/4.0/

(c) (i) Open Access

\begin{abstract}
The present study examined the potential of Mindfulness Art Therapy Short version on mood of healthy people. The Mindfulness Art Therapy Short version consisted of two sessions and included factors of both mindfulness and art therapy. The Art Therapy alone consisted of two sessions including factors of art therapy. Seventeen college students received the Mindfulness Art Therapy Short version and twenty-two students received Art Therapy alone. All participants completed the Profile of Mood States pre- and post-interventions in each session. In the Mindfulness Art Therapy Short version group, scores for Tension-Anxiety, Depression-Dejection, and Fatigue-Inertia reduced and those for Vigor-Activity significantly increased after the program. In the Art Therapy group, although scores for Tension-Anxiety and Fatigue-Inertia decreased, the scores of Depression-Dejection and Vigor-Activity did not significantly change. The score of Total Mood significantly decreased only in the Mindfulness Art Therapy Short version. These results suggest that the Mindfulness Art Therapy Short Version may be more affective for improving mood, particularly depression and vigor, compared to Art Therapy alone.
\end{abstract}

\section{Keywords}

Mindfulness Art Therapy, Mood, Fatigue, Vigor

\section{Introduction}

Cancer patients often experience symptoms of anxiety, depression, and fatigue. Art Therapy may be effective psychotherapy for these symptoms, as a complementary therapy and a clinical intervention based on the belief that the creative process involved in making of art is healing and life-enhancing [1]. Art Therapy has been

${ }^{*}$ Corresponding author. 
shown to be effective for anxiety [2], depression [3] and spiritual well-being [4], but has not been examined for its effects on fatigue or vigor.

On the other hand, the mindfulness approach is another type of psychotherapy. The Mindfulness-Based Stress Reduction (MBSR) program is modeled on the work of Kabat-Zinn and colleagues at the Center for Mindfulness at the Massachusetts Medical Center [5]. The program is based on the principle of mindfulness, which is defined as moment-to-moment, present-centered, purposive non-judgmental awareness. The goal of the MBSR program is to guide participants to achieve greater awareness of themselves, their thoughts, and their bodies through class discussion, meditation, and yoga exercises. The program is effective for mood disturbance and stress symptoms [6], immune profile [7], spirituality [8], and sense of coherence [9].

Since both the Art Therapy and Mindfulness approach were effective on psychological aspects, there is a previous study which integrated those therapies. Mindfulness Art Therapy is a psychotherapy in which mindfulness meditation skills and aspects of art therapy are integrated. Mindfulness Art Therapy conducted for eight weeks as a supportive therapy has a positive effect on QOL of cancer patients [10]. However, it may be difficult for cancer patients with advanced cancer to attend an eight-week group program, and therefore we have developed a Mindfulness Art Therapy Short version. It consisted of two sessions: a session was conducted individually, and participants could perform yoga or meditation in sitting. Also, our target patients tend to become easily fatigued and to lose vigor, and therefore we designed the program to alleviate fatigue and elevate vigor.

In the present study, we examined the effect of the Mindfulness Art Therapy Short version program on mood, and particularly on fatigue and vigor, in healthy adults, as a preliminary study before examining efficacy in cancer patients. Use of a randomized control group would have been preferable, but this was not possible because of the use of college students as participants. Therefore, we examined mood of healthy people who received the Mindfulness Art Therapy Short version and Art Therapy alone.

The purpose of the present study was to examine mood of healthy people who received the Mindfulness Art Therapy Short version and those received Art Therapy alone.

\section{Methods}

\subsection{Participants}

The participants were 39 students at a single college in Japan. This study was performed in the class at a college. Students of the two classes participated. Before a class, a researcher explained about the research, if a student had intention to participate the study, he submitted questionnaires after the class. Seventeen students of a class received the Mindfulness Art Therapy Short version (Figure 1), and 22 students of another class received Art Therapy alone. The inclusion criterion was age $>20$ years old and the exclusion criterion was the presence of severe mental problems. All subjects participated voluntarily and the study was approved by the ethical board of an author's college.

\subsection{Measures}

The Japanese Profile of Mood States (POMS) short version [11], which is based on the original version [12], was used to measure mood states using a Likert-type scale. It measures the Total Mood and 6 subdomains. The subdomains and $\alpha$ reliability were followings; Tension-Anxiety (0.83), Depression-Dejection (0.84), AngerHostility (0.84), Vigor-Activity (0.85), Fatigue-Inertia (0.88), and Confusion-Bewilderment (0.59). A validity was approved by high coefficient correlation (above 0.9 in each domain) between the short version and the full version in Japanese, and this short version was standardized. The POMS can measure both changes pre and post intervention in one session and those in the first session and the second session, then we used pre and post in each session.

\subsection{Procedures}

In the Mindfulness Art Therapy Short Version group, participants received mindfulness therapy included breathing, yoga with gentle movement, and body scan in which they concentrated their attention to their bodies taught by a yoga specialist and a psychologist for about 20 minutes. After that, they made arts items using clay, collage (fancy paper, felt glue sticks, magazines), or drawing (color pencils, pastel chalk, pencils, water colors) about 40 minutes (Figure 2). After the session, participants were recommended to perform mindfulness as home 


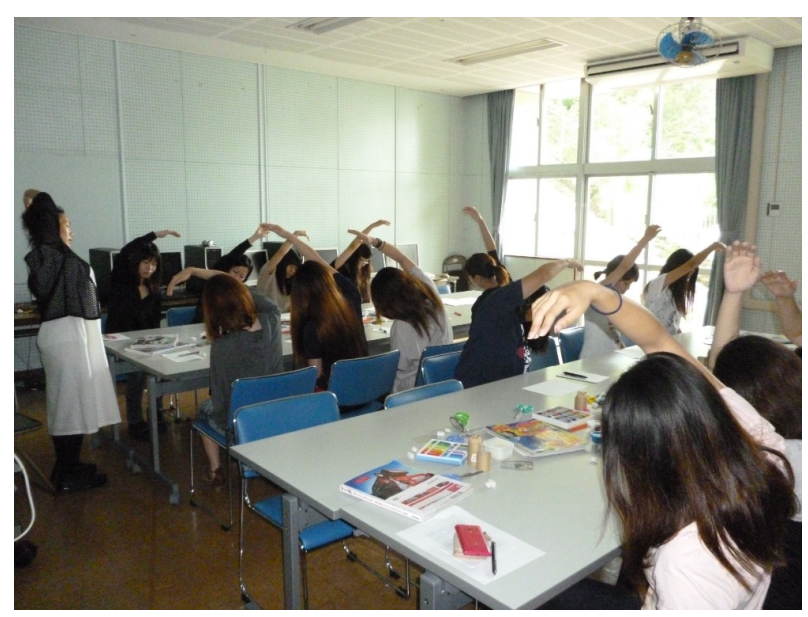

Figure 1. The scene of mindfulness in the Mindfulness Art Therapy short version.

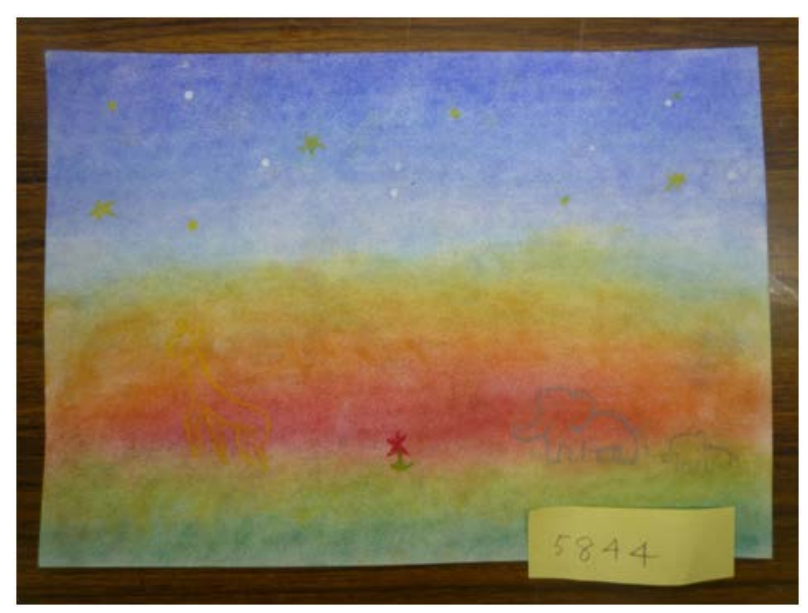

Figure 2. A sample of art item by a participant.

work. After two weeks, a second session was held, and in which they performed like the first session. In the Art Therapy group, participants made art items using clay, collage, or drawing without mindfulness about $60 \mathrm{mi}-$ nutes. After two weeks, a second session was held, and in which they made art items like the first session. Participants completed the POMS pre and post in each session.

\subsection{Analysis}

A p value less than 0.05 was taken to indicate a significant level in all analyses. All reported p values are 2tailed. Statistical procedures were conducted with SPSS ver. 21.0 (Japanese version) for Windows (SPSS Inc.). Scores of the subdomains of the POMS pre intervention in the first session and those of post intervention in the second session were compared by t-test, and total mood were compared pre and post in each session by t-test, because there was difference at the baseline score between the Mindfulness Art Therapy Short version and the Art Therapy groups.

\section{Results}

The pre-intervention POMS scores showed no clinical problems in the Mindfulness Art Therapy Short version and Art Therapy groups, since the scores were below the standard level [11].

In the Mindfulness Art Therapy Short version group, the POMS scores changed from $3.06 \pm 3.24$ pre-therapy to $0.90 \pm 2.14$ post-therapy for Tension-Anxiety, from $1.94 \pm 2.10$ to $0.65 \pm 1.49$ for Depression-Dejection, from 
$0.59 \pm 1.19$ to $0.41 \pm 1.24$ for Anger-Hostility, from $5.23 \pm 3.32$ to $7.82 \pm 5.40$ for Vigor-Activity, from $4.71 \pm$ 3.14 to $1.12 \pm 1.81$ for Fatigue-Inertia, and from $4.06 \pm 1.59$ to $3.82 \pm 0.71$ for Confusion. Scores for TensionAnxiety, Depression-Dejection, and Fatigue-Inertia reduced and that for Vigor-Activity significantly increased after the program (Table 1$)$.

In the Art Therapy group, the POMS scores changed from $5.54 \pm 3.87$ pre-therapy to $3.31 \pm 3.73$ post-therapy for Tension-Anxiety, from $1.90 \pm 1.44$ to $1.73 \pm 2.82$ for Depression-Dejection, from $0.86 \pm 1.22$ to $1.45 \pm 4.16$ for Anger-Hostility, from $6.72 \pm 4.17$ to $7.50 \pm 5.37$ for Vigor-Activity, from $6.27 \pm 4.90$ to $4.32 \pm 4.72$ for Fatigue-Inertia, and from $6.68 \pm 2.40$ to $6.27 \pm 2.94$ for Confusion. Scores for Tension-Anxiety and Fatigue-Inertia significantly decreased (Table 2).

Moreover, the Total Mood score significantly decreased from $9.12 \pm 10.2$ to $-0.94 \pm 9.64$ in the first session, and the score decreased from $9.53 \pm 20.3$ to $2.59 \pm 18.24$ in the second session of the Mindfulness Art Short Version. On the other hand, the Total Mood score decreased from $14.5 \pm 12.0$ to $9.59 \pm 17.5$ in the first session and score decreased from $16.4 \pm 14.9$ to $11.8 \pm 14.4$ in the second session of the Art Therapy group. The score of Total Mood significantly decreased only in the Mindfulness Art Therapy Short version.

\section{Discussion}

The Mindfulness Art Therapy Short version was effective for alleviating tension-anxiety, depression and fatigue, and elevating vigor, whereas the Art Therapy alone was effective for alleviating tension-anxiety and fatigue. These results suggest that the Mindfulness Art Therapy Short version may be more effective for improving mood compared to the Art Therapy alone. This may partly be explained by Mindfulness in which participants learned to concentrate their attention on their mind and body, to mediate their feelings or thoughts cognitively, and feel energy from inside their body. Moreover, they could express their feelings or energy and their vigor might increase.

The effects of Mindfulness Art Therapy Short version on "anxiety" and "depression" are consistent with studies showing the efficacy of the Art Therapy for these symptoms [3] [13] and with studies relating mindfulness to improvement of anxiety and depression [9], anxiety [14] [15], and mood [8].

The efficacy of the Mindfulness Art Therapy Short version for fatigue and vigor is of particular interest. Nainis et al. [1] showed the efficacy of art therapy for physical symptoms such as pain, tiredness, appetite, or breathlessness measured by the Edmonton Symptom Assessment Scale, however not on vigor or fatigue. To our knowledge, the efficacy of the Mindfulness Art Therapy on fatigue or vigor may be important.

As for Total Mood of the POMS, although scores of both the Mindfulness Art Therapy Short version group and Art therapy group decreased pre- and post-intervention (Table 3), only significance was observed in Mindfulness Art Therapy Short version group. It may suggest that this therapy is more effective on mood.

Table 1. Pre- and post-intervention scores for subdomains of the Profile of Mood States (POMS) scale in the Mindfulness Art Therapy group $(\mathrm{n}=17)$.

\begin{tabular}{|c|c|c|c|c|}
\hline & Pre & Post & t-value & $\mathrm{p}$ value \\
\hline Tension-Anxiety & $3.06 \pm 3.24$ & $0.90 \pm 2.14$ & 2.91 & $\mathrm{p}<0.01^{* *}$ \\
\hline Depression-Dejection & $1.94 \pm 2.10$ & $0.65 \pm 1.49$ & 3.16 & $\mathrm{p}<0.05^{*}$ \\
\hline Fatigue-Inertia & $4.71 \pm 3.14$ & $1.12 \pm 1.81$ & 5.31 & $\mathrm{p}<0.001^{* * *}$ \\
\hline Vigor-Activity & $5.23 \pm 3.32$ & $7.82 \pm 5.40$ & -2.41 & $\mathrm{p}<0.03^{*}$ \\
\hline Anger-Hostility & $0.59 \pm 1.19$ & $0.41 \pm 1.24$ & 0.43 & $\mathrm{p}>0.68$ \\
\hline Confusion & $4.16 \pm 1.59$ & $3.82 \pm 0.71$ & 0.62 & $\mathrm{p}>0.54$ \\
\hline
\end{tabular}

Table 2. Pre- and post-intervention scores for subdomains of the Profile of Mood States (POMS) scale in the Art Therapy group $(n=22)$.

\begin{tabular}{|c|c|c|c|c|}
\hline & Pre & Post & t-value & $\mathrm{p}$ value \\
\hline Tension-Anxiety & $5.54 \pm 3.87$ & $3.31 \pm 3.73$ & 2.93 & $\mathrm{p}<0.05^{*}$ \\
\hline Depression-Dejection & $1.90 \pm 1.44$ & $1.73 \pm 2.82$ & 0.32 & $\mathrm{p}>0.75$ \\
\hline Fatigue-Inertia & $6.27 \pm 4.90$ & $4.32 \pm 4.72$ & 2.38 & $\mathrm{p}<0.03^{*}$ \\
\hline Vigor-Activity & $6.72 \pm 4.17$ & $7.50 \pm 5.37$ & -0.95 & $\mathrm{p}>0.35$ \\
\hline Anger-Hostility & $0.86 \pm 1.22$ & $1.45 \pm 4.16$ & -0.64 & $p>0.53$ \\
\hline Confusion & $6.68 \pm 2.40$ & $6.27 \pm 2.94$ & 0.54 & $p>0.59$ \\
\hline
\end{tabular}


Table 3. Scores of total mood of the POMS.

\begin{tabular}{|c|c|c|c|c|}
\hline Session & Pre & Post & t-value & $\mathrm{p}$ value \\
\hline 1st MAT & $9.12 \pm 10.2$ & $-0.94 \pm 9.64$ & 4.25 & $\mathrm{p}<0.001^{* * *}$ \\
\hline 2nd MAT & $9.53 \pm 20.3$ & $2.59 \pm 18.24$ & 1.57 & $p>0.14$ \\
\hline 1st AT & $14.5 \pm 12.0$ & $9.59 \pm 17.5$ & 1.42 & $\mathrm{p}>0.17$ \\
\hline 2nd AT & $16.4 \pm 14.9$ & $11.8 \pm 14.4$ & 1.77 & $p>0.09$ \\
\hline
\end{tabular}

MAT: Mindfulness Art Therapy Short version, AT: Art Therapy

Lastly as limitations, the study is limited by the small number of participants totally. Thus, evaluation of the robustness and reliability of the findings will require a further study in more subjects. Moreover, we did not set a randomized controlled study, and then in order to obtain robust data, we need to use the randomized controlled study.

\section{Acknowledgements}

This study was supported by JSPS KAKENHI grant number 245309010001.

\section{References}

[1] Nainis, N., Paice, J.A., Ratner, J., Wirth, J.H., Lai, J. and Shott, S. (2006) Relieving Symptoms in Cancer: Innovative Use of Art Therapy. Journal of Pain and Symptom Management, 31, 162-169. http://dx.doi.org/10.1016/j.jpainsymman.2005.07.006

[2] Oster, I., Svensk, A.C., Magnusson, E., Thyme, K.E., Sjodin, M., Astrom, S. and Lindh, J. (2006) Art Therapy Improves Coping Resources: A Randomized, Controlled Study among Women with Breast Cancer. Palliative and Supportive Care, 4, 54-64. http://dx.doi.org/10.1017/S147895150606007X

[3] Bar-Sela, G., Atid, L., Danos, S., Gabay, N. and Epelbaum, R. (2007) Art Therapy Improved Depression and Influenced Fatigue Levels in Cancer Patients on Chemotherapy. Psychooncology, 16, 980-984. http://dx.doi.org/10.1002/pon.1175

[4] Vella, E. and Budd, M. (2011) Pilot Study: Retreat Intervention Predicts Improved Quality of Life and Reduced Psychological Distress among Breast Cancer Patients. Complimentary Therapies in Clinical Practice, 17, 209-214. http://dx.doi.org/10.1016/j.ctcp.2011.01.005

[5] Kabat-Zinn, J. (1990) Full Catastrophe Living: Using the Wisdom of Your Body and Mind to Face Stress, Pain and Illness. Delacourt, New York.

[6] Speca, M., Carlson, L.E., Goodey, E. and Angen, M. (2000) A Randomized, Wait-List Controlled Clinical Trial: The Effect of a Mindfulness Meditation-Based Stress Reduction Program on Mood and Symptoms of Stress in Cancer Outpatients. Psychosomatic Medicine, 62, 613-622.

[7] Carlson, L.E., Speca, M., Patel, K.D. and Goodey, E. (2004) Mindfulness-Based Stress Reduction in Relation to Quality of Life, Mood, Symptoms of Stress and Levels of Cortisol, Dehydroepiandrosterone Sulfate (DHEAS) and Melatonin in Breast and Prostate Cancer Outpatients. Psychoneuroendocrinology, 29, 448-474. http://dx.doi.org/10.1016/S0306-4530(03)00054-4

[8] Garland, S.N., Carson, L.E., Cook, S., Lansdell, L. and Speca, M. (2007) A Non-Randomized Comparison of Mindfulness-Based Stress Reduction and Healing Arts Programs for Facilitating Post-Traumatic Growth and Spirituality in Cancer Outpatients. Supportive Care in Cancer, 15, 949-961. http://dx.doi.org/10.1007/s00520-007-0280-5

[9] Ando, M., Natsume, T. and Kukihara, H. (2011) Efficacy of Mindfulness-Based Meditation Therapy on the Sense of Coherence and Mental Health of Nurses. Health, 3, 118-122. http://dx.doi.org/10.4236/health.2011.32022

[10] Monti, D.A., Peterson, C. and Kunkel, S. (2006) A Randomized, Controlled Trial of Mindfulness-Based Art Therapy (MBAT) for Women with Cancer. Psycho-Oncology, 15, 363-373. http://dx.doi.org/10.1002/pon.988

[11] Yokoyama, K. (2010) POMS Short Version: Tebiki to Jirei Kaisetsu. Kaneko Syobo, Japan. (in Japanese)

[12] McNair, D.M., Lorr, M. and Droppelman, L.F. (1971) EDITS Manual for the Profile of Mood States. Educational and Industrial Testing Service, San Diego.

[13] Puig, A., Lee, S.M., Goodwin, L. and Sherrard, P. (2006) The Efficacy of Creative Arts Therapies to Enhance Emotional Expression, Spirituality, and Psychological Well-Being of Newly Diagnosed Stage and Stage Breast Cancer Patients: A Preliminary Study. The Arts in Psychotherapy, 33, 218-228. http://dx.doi.org/10.1016/j.aip.2006.02.004 
[14] Tacon, A.M., Caldera, Y.M. and Ronaghan, C. (2004) Mindfulness-Based Stress Reduction in Women with Breast Cancer. Families Systems Health, 22, 193-203. http://dx.doi.org/10.1037/1091-7527.22.2.193

[15] Tacon, A.M., Caldera, Y.M. and Ronaghan, C. (2005) Mindfulness, Psychosocial Factors, and Breast Cancer. Journal of Cancer Pain and Symptom Palliation, 1, 45-53. http://dx.doi.org/10.3109/J427v01n01_06 